\title{
Facebook Addiction and Emerging Adults: The influence of sociodemographic variables, family communication, and differentiation of self
}

\section{Adicción a Facebook y adultos emergentes: La influencia de variables sociodemográficas, comunicación familiar y diferenciación del self}

\author{
Luciana Sotero, Gustavo Ferreira da Veiga, Daniela Carreira, Alda Portugal \& Ana P. Relvas \\ University of Coimbra, Portugal
}

\begin{abstract}
The growing use of social networking sites places them among the most popular online activities. In particular, Facebook is gaining increasing numbers of users. For some individuals, such activity can develop into addictive online behaviour. The main objective of this study was to assess the influence of sociodemographic (e.g., gender, age), individual (e.g., differentiation of self), and family (e.g., family communication) factors on Facebook addiction in Portuguese emerging adults aged between 18 and 30 years. The study included 403 participants, who followed a protocol in which several instruments were administered (e.g., COMPA, BSI, DSI-R, and BFAS). The results showed higher Facebook use and a higher risk of addiction in individuals with the following characteristics: (1) female gender; (2) aged between 24 and 30 years; (3) lower differentiation of self; (4) physically or emotionally distanced from significant others (emotional cut-off); and (5) negative communication patterns with their parents. An association was also found between other psychopathological indicators (e.g., depression, anxiety, and interpersonal sensitivity) and Facebook use. Thus, the present study contributes to the field of research on online addictions and has implications for prevention and clinical intervention
\end{abstract}

Keywords: Social Networking Sites; Facebook Addiction; Emerging Adults; Family Communication; Differentiation of Self.

\begin{abstract}
Resumen
El uso creciente de las redes sociales los ubica entre las actividades on-line más populares. Facebook, en particular, está ganando más y más usuarios y para algunas personas puede convertirse en un comportamiento adictivo on-line. El objetivo principal de este estudio fue evaluar la influencia de factores sociodemográficos (e.g., género, edad), individuales (e.g., diferenciación del self) y familiares (e.g., comunicación familiar) en la adicción a Facebook, dentro de la población portuguesa de adultos emergentes (edad entre 18-30). Para este propósito, se recolectó una muestra de 403 participantes y se aplicó un protocolo con varios instrumentos (por ejemplo, COMPA, BSI, DSI-R, BFAS). Los resultados mostraron que las personas: (1) mujeres, (2) con edades comprendidas entre 24 y 30 años, (3) con menor diferenciación del self, (4) que se distancian física o emocionalmente de otras personas importantes (corte emocional) y (5) quienes usan un patrón negativo de comunicación con sus padres muestran un mayor uso de Facebook y un mayor riesgo de adicción. También se analizaron otros indicadores psicopatológicos (por ejemplo, depresión, ansiedad y sensibilidad interpersonal), revelando que están asociados con el adicción a Facebook. Por lo tanto, el presente estudio contribuye al campo de la investigación sobre las adicciones a internet y tiene repercusiones en la prevención y la intervención clínica.
\end{abstract}

Palabras clave: Redes sociales on-line; Adicción a Facebook; Adultos emergentes; Communication familiar; Differentiation del self.

Please cite this article as: Sotero, L., Ferreira da Veiga, G. Carreira, D., Portugal, A. \& Relvas, A. P. (2019). Facebook Addiction and Emerging Adults: The influence of sociodemographic variables, family communication, and differentiation of self. Escritos de Psicología, 12, 81-92.

Correspondencia: Luciana Sotero. Faculty of Psychology and Educational Sciences, University of Coimbra, Rua do Colégio Novo, 3000-115 Coimbra, Portugal; Centre for Social Studies (CES), University of Coimbra, Colégio de S. Jerónimo, Largo D. Dinis, 3000-995 Coimbra, Portugal. E-mail: lucianasotero@fpce.uc.pt 


\section{Introduction}

As Internet becomes increasingly part of our daily lives, Social Networking Sites (SNSs) (e.g. Facebook, Twitter) have grown exponentially in popularity, becoming a global phenomenon. SNSs can summarily be defined as virtual communities that allow individuals to create personal profiles to connect and socialize with others (Holmgren \& Coyne, 2017). Albeit being an especially popular activity among teenagers, the number of young adults users has been rising (Perrin, 2015). Emerging adults (18-30 years old) are the first to have been exposed or used SNS for the first 18 years of their lives (Coyne, Padilla-Walker, \& Howard, 2013). Within SNSs, Facebook is by far the most popular worldwide. Due to its features, it allows different forms of communication through different applications: email, instant messaging, posts, photos and comments (Moreau, Laconi, Delfour, \& Chabrol, 2015). In Portugal, more than 5 million people currently use Facebook (Statista, 2019).

Recent investigations have focused on excessive use, originating reports of addictive behaviors, both to the Internet and the its content (Kuss \& Billieux, 2016). As with other online behaviors, excessive Facebook use can be considered an addictive behavior (Andressen, Torsheim, Brunborg, \& Pallensen, 2012). Investigations have focused on the impact that addictions have on individuals and their interpersonal relations (Moreau et al., 2015), as well as on understanding what may be the predisposing factors of SNS and Facebook addiction (Andreassen, 2015; Holmgren \& Coyne, 2017; Przepiorka \& Blachnio, 2016).

Several studies have addressed the importance of individual factors (e.g., isolation, depression, anxiety disorders) as well as family factors (e.g., family communication) (Bridges, Griffiths, \& Patrão, 2014), but there is still a lack of empirical work, particularly within the emerging adult population. Accordingly, this research aims to identify Facebook addiction within the emerging adult population (aged between 18 and 30 years), as well as sociodemographic, individual and family factors that may influence such addition, thus contributing to the clinical understanding and intervention, as well as to scientific knowledge in this subtype of technological addition.

\section{Social Networking Sites: The Facebook case}

Has SNS use rises, many have highlighted its focus on social connections (Kuss \& Griffiths 2017). In fact, SNSs are virtual communities where users can: (1) create a public or semi-public profile, (2) manage a list of connections with other users, and (3) view and intersect their list of connections with those made by other users (Boyd \& Ellison, 2008). Although SNS are distinguished by their particularities, they all facilitate social interaction by disseminating information to a chosen audience, which varies according to SNS in use (Boyd and Ellison, 2008). Connections made are not just about meeting and connecting with new people, but also about keeping in touch with those who were already in their offline social network. This emphasis on connecting with others pertains to fundamental human needs, such as social support and self-expression (Andreassen et al., 2012; Kuss \& Griffiths, 2011). With increasing devices and means (e.g., smartphones), accessing SNSs is becoming faster and easier, making users more vulnerable to their overuse (Kuss \& Griffiths, 2011).

Within SNSs, Facebook continues to be the most popular, with an exponential increase in Portugal in recent years (INE, 2015). Facebook brings together numerous features that give it a particular character. Although the main drive behind its use is to maintain and establish relationships (Andreassen et al., 2012), it also allows for other purposes, such as entertainment, procastination, escaping negative emotions, among others (Ryan, Chester, Reece, \& Xenos, 2014). With the growing number of users, Facebook has been developing different applications and releasing new updates to make it more attractive to those already using the SNS and to attract others. Currently, it encompasses the possibility of selling/buying products, localization system and project sharing and dissemination tools (Kuss \& Griffiths, 2017).

\section{Technological Additions: Additions of Modern Society}

Like other Internet applications, SNS have many positive aspects: increased social support, self-exploration and self-discovery and better self-esteem after receiving positive feedback from friends, plus the great advantage of re-establishing / maintaining contacts with family and friends. (Holmgren \& Coyne, 2017). For instance, families with young adults use new technologies to cope with problems, thus contributing to better family functioning (Carvalho, Francisco, \& Relvas, 2017). Despite this, several studies also have highlighted some negatives aspects, such as decreases in social participation offline, academic performance, and interpersonal problems (Kuss \& Griffiths, 2011). Accordingly, some studies suggest that addiction to online social networks may be a potential mental health problem for some users (Kuss \& Griffiths, 2011). 
The great involvement with new technologies can lead to additive behaviors, wich have been conceptualized as technological additions (Kuss \& Griffiths, 2017). According to Griffiths (2005), technological additions can be defined as non-chemical, behavioral additions that involve human-machine interaction. These can be characterized as active (e.g., playing video games) or passive (e.g., see television). According to Griffiths (2013), SNS addiction may be categorized as a behavioral addiction within a biopsychosocial framework, with the presence of six core components: salience (1), mood modification (2), tolerance (3), withdrawal symptoms (4), conflict (5) and relapse (6) (Griffiths, 2005). Technological additions are part of a bio-psychosocial process, resulting from the interaction of individual, social and specific factors of the activity itself that allow on the whole to understand the additive behaviors and distinguish them from behaviors that do not have these characteristics (Griffiths, 2005).

\section{Empirical studies evidence of Facebook adiction}

Online additions investigations (e.g., Internet addiction, Gaming addiction) have recently emphasized SNS Addiction research (Kuss \& Griffiths, 2011). Accordingly, investigations conducted in this area have sought to understand intra and interpersonal factors that may influence SNS addition. Studies also report the presence of factors and characteristics of individuals that may favour addition to Facebook. In a study conducted by Przepiorka and Blachnio (2016), younger age and longer time spent using Facebook were identified as determinants of Facebook addiction. With regard to gender, although some studies refer to this addition as being associated with males (Çam \& Ísbulan, 2012), other studies point to a higher prevalence of females in the addition to Facebook (Przepiorka \& Blachnio, 2016), adding that many of the Facebook applications are more attractive to women. Some studies show that most users are female and it is women who spend more time on Facebook (Hargittai, 2007; McAndrew \& Jeong, 2012; Soron \& Tarafder, 2015). Since the addition to this network is predicted by its level of use, it is possible that they are also more likely to add to Facebook than men. Also, in this regard, there is a higher number of female users (51.4\%), although not far from the percentage presented by male users $(48.6 \%)$ (GlobalStat, 2019). Females show greater use of mobile phones as a way of maintaining relationships, while males make more use of email (Carvalho et al., 2017). Regarding marital status, single people spend more time on Facebook (Soron \& Tarafder, 2015). Committed men are also found to spend less time viewing women's pages, posting or commenting on photographs. For women, being (or not) compromised seems to be irrelevant to their use of Facebook. This may mean that men use Facebook as a search tool rather than women (McAndrew \& Jeong, 2012; Soron \& Tarafder, 2015). Thus, marital status is understood to have an impact on male activity on Facebook, but little effect on females (McAndrew \& Jeong, 2012). Thus, sociodemographic characteristics such as a person's gender, age, or marital status may be important in studying Facebook addiction, making sense to study these relationships in order to deepen understanding and the possibilities for intervention in this area (McAndrew \& Jeong, 2012).

Gratifications that SNSs can provide are a determining factor in addition, since individuals may experience a loss of control in their use, motivated by obtaining them (Song, LaRose, Eastin, \& Lin, 2004). Thus, research conducted in this area has sought to understand which intra and interpersonal factors may influence the addition to SNSs (Ryan et al., 2014). According to the literature, there is a gender differentiated demand, with males using social networks more to reinforce personal compensation and gambling, while females use them more as a means of communicating with their peers (Barker, 2009).

According to the literature review, there are few studies that analyse the influence of family factors on the addition to Facebook. However, a Portuguese study on the use of Information and Communication Technologies (ICTs) within the family states that in families with young adults, the concern lies in the number of ICTs used, with a higher quantity being associated with the risk of addition, since young adults spend more time online, as they are autonomous in managing that time (Carvalho et al., 2017). This research also reveals that in families with young adults, ICTs are also used for the benefit of their members, helping families to deal with some problems and difficulties and to contribute to a better functioning (Carvalho et al., 2017).

With regard to psychopathological factors, depression and anxiety seem to be strongly associated with addiction, revealing that anxious and avoiding individuals prefer online social interaction, since face-to-face communication is more anxious for them (Chabrol, Laconi, Delfour, \& Moreau, 2017; Moreau et al., 2015). Other studies show that people with smaller interpersonal support networks are more introverted and more dissatisfied with life, which may lead them to use Facebook to overcome these difficulties in their lives (Przepiorka \& Blacchnio, 2016).

In summary, the empirical evidence on Facebook Addiction allows us to conclude that despite the various individual markers studied, there are practically no studies that relate family and personal characteristics, such as the differentiation of self and family communication with Facebook Addiction. 


\section{The present Study}

Given the aforementioned rationale, and following the studies carried out with the Portuguese version of Bergen Facebook Addiction Scale (BFAS; da Veiga et al., 2019), this research aims to identify the influence of sociodemographic, familiar and individual variables on Facebook Addiction in a sample of emerging adults (cf. Figure 1). To this end, the following specific objectives were defined:

1. To explore the influence of gender, age, area of residence, relational status, educational level, employment status and sports pratice or hobbies on Facebook Addiction (sociodemographic variables).

2. To investigate the influence of communication with each parent (i.e., father, mother) on Facebook Addiction (family variables).

3. To analyse the influence differentiation of self on Facebook Addiction (individual variable).

4. To evaluate the relationship between Facebook Addiction and psychopathological dimensions (e.g., Interpersonal sensitivity, Anxiety and Depression).

\section{Figure 1}

Study conceptual map

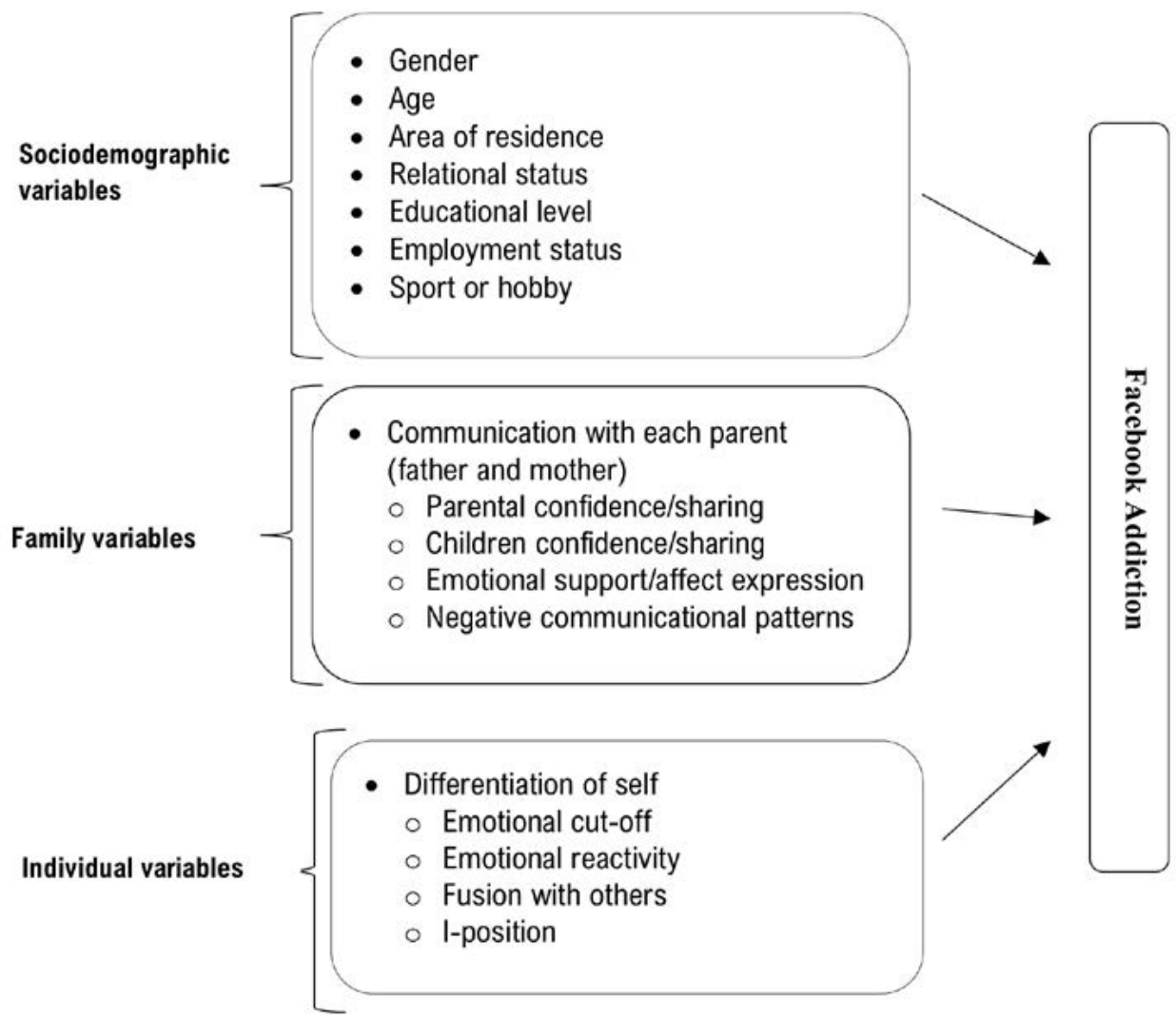

\section{Participants and Procedure}

\section{Methods}

The sample was selected on the basis of availability, through a non-random sampling method, between January and April 2019. All data obtained remained anonymous and confidential and no financial rewards were provided to participants. The inclusion criteria used was: a) age between 18 and 30 years old; b) Portuguese nationality; c) Facebook user.

Data was collected from 403 individuals, aged between $18-30$ years $(M=22.25 ; S D=3.24)$. Most participants were women $(65.5 \%)$, residing in urban areas $(46.3 \%)$. The majority of individuals are students $(63.7 \%)$, with the $9^{\text {th }}$ grade completed $(29.9 \%)$, a similar number tho those who have completed the $12^{\text {th }}$ grade $(29.6 \%)$ (see Table 1$)$. With regard to sports, the majority of subjects reported that they do not practice any type of activity (59.0\%). Regarding hobbies, a slightly higher value of individuals claim to have an extracurricular/labour activity $(51.1 \%)$. A larger number of participants reported sleeping more than 8 hours of sleep per day (53.8\%). Regarding Facebook use, the majority of subjects report having a personal page $(96.8 \%)$, mainly using Facebook for conversation $(88.9 \%)$ and informative content $(56.2 \%)$. The average daily use of Facebook is about 114 minutes, i.e., approximately two hours (see Table 2). 
Table 1

\begin{tabular}{|c|c|c|c|}
\hline & Sociodemographic variables & $N$ & $\%$ \\
\hline \multirow[t]{2}{*}{ Gender } & Female & 264 & 65.5 \\
\hline & Male & 139 & 34.5 \\
\hline \multirow[t]{2}{*}{ Age } & $18-23$ & 263 & 66.6 \\
\hline & $24-30$ & 132 & 33.4 \\
\hline \multirow[t]{3}{*}{ Residence Area } & Urban & 184 & 46.3 \\
\hline & Semi-urban & 111 & 28.0 \\
\hline & Rural & 102 & 25.7 \\
\hline \multirow[t]{5}{*}{ Relationship Status } & Single & 212 & 52.6 \\
\hline & In a relationship & 165 & 40.9 \\
\hline & Living together, unmarried & 16 & 4.0 \\
\hline & Married & 8 & 2.0 \\
\hline & Divorced & 2 & 0.5 \\
\hline \multirow[t]{5}{*}{ Education } & 9th grade & 118 & 29.9 \\
\hline & 12th grade & 117 & 29.6 \\
\hline & Bachelor's Degree & 115 & 29.1 \\
\hline & Master's Degree & 35 & 89 \\
\hline & $\mathrm{PhD}$ & 1 & 0.3 \\
\hline \multirow[t]{4}{*}{ Occupational Status } & Studying & 260 & 66.0 \\
\hline & Working & 117 & 29.7 \\
\hline & Unemployed & 19 & 4.8 \\
\hline & Working/Studying & 7 & 1.8 \\
\hline \multirow[t]{2}{*}{ Sports practice } & Yes & 163 & 41.0 \\
\hline & No & 235 & 59.0 \\
\hline \multirow[t]{2}{*}{ Hobbies } & Yes & 202 & 51.1 \\
\hline & No & 193 & 48.9 \\
\hline
\end{tabular}

Following a criterion suggested in the BFAS original study - scoring 3 or above on at least four of the six items (Andreassen et al., 2012) - a subsample of individuals with higher levels of addiction was found. This subsample comprised of 30 participants, 19 females (63.3\%), with a mean age of 22.17 years $(S D=3.45)$. The majority of individuals were resident in urban areas $(63.3 \%)$, reported to be students $(76,7 \%)$ with the $12^{\text {th }}$ grade completed $(50 \%)$. Most participants of this subgroup were not in a relationship (56.7\%). In its relation to types of Facebook use, almost all participants reported using this SNSs for conversations (96.7\%), 66.7\% reported accessing information content, 63.3\% reported using Facebook to view multimedia content, $26.7 \%$ for gaming, 3.3\% for purchases and none for viewing erotic content. Among the potentially addicted participants, Facebook's average daily usage was 196.67 minutes $(S D=187.42)$.

\section{Measures}

Sociodemographic and Facebook Usage Survey

Specifically designed for the present study this survey included questions about participants sociodemographic data (age, gender, locality, education, occupational status, relationship status, practice of sports and/or hobbies, sleep routines) and related to Facebook use (daily time spent on the platform, activities usually developed and content viewed).

Table 2

Facebook Usage

\begin{tabular}{llcc}
\hline Facebook variables & & $N$ & $\%$ \\
\hline Facebook Personal page & Yes & 389 & 96.8 \\
Facebook's average daily usage(minutes) & No & 13 & 3.2. \\
& $1-30$ & 82 & 20.3 \\
& $31-60$ & 76 & 18.7 \\
& $61-90$ & 44 & 10.7 \\
& $91-120$ & 44 & 10.7 \\
& $121-150$ & 21 & 5.1 \\
& $151-180$ & 20 & 5.0 \\
& $181-210$ & 12 & 2.9 \\
Activities pursued/ content viewed & $211-240$ & 10 & 2.5 \\
& $241-270$ & 3 & 0.7 \\
& $271-300$ & 3 & 0.7 \\
& +300 & 25 & 5.8 \\
& Multimedia & 180 & 45.3 \\
& Conversation & 353 & 88.9 \\
& Information & 223 & 56.2 \\
& Purchases & 31 & 7.8 \\
& Gaming & 49 & 12.3 \\
& Erotic & 4 & 1.0
\end{tabular}


Bergen Facebook Addiction Scale (BFAS)

The BFAS (Andreassen et al., 2012; Portuguese version da Veiga et al., 2019) seeks to assess Facebook addiction. It is six items self-report scale, each item corresponding to one of the six central components of the addiction, according to the model proposed by Griffiths (2005): salience, mood modification, tolerance, withdrawal symptoms, conflict and relapse. Referring to the last twelve months, the items are scored between 1 (Very Rarely) and 5 (Very Frequently) (e.g., "How often during the last year did you used Facebook in order to forget about personal problems?"). The overall score ranges from 6 to 30, with higher scores reflecting a greater addiction to Facebook (Andreassen et al., 2012). The original authors have suggested that scoring three or more in four of the six items is an addiction indicator (Andreassen et al., 2012). The original version of the BFAS revealed good psychometric properties, namely good internal consistency $(\alpha=.83)$, test-retest reliability $(r=.82)$, convergent validity with related scales and a one-factor structure with good fit indicators (RMSEA $=.046, \mathrm{CFI}=.99$ ). The recent Portuguese validation of the instrument with emerging adults also revealed good internal consistency $(\alpha=.85)$ (da Veiga et al., 2019). In the present study, a good internal consistency value $(\alpha=.77)$ was obtained, albeit lower than that reported in previous studies.

\section{Perception Scale of Parenting Communication - Emerging Adults (COMPA-EA)}

Originally developed by Portugal and Alberto (Portugal \& Alberto, 2013), COMPA is a self-report scale that evaluates communication patterns between parents and children. There are several versions of the scale, depending to whom it applies (parents or children) and the age of the children, and in this study we used the version for emerging adult children aged between 18 and 25 years (Portugal et al., 2019). The scale is composed of two parts, one part about the communication with the father (stepfather, grandfather, uncle or male element who assumes parental responsibilities) and other about the communication with the mother (stepmother, grandmother, aunt or other female element who assumes parental responsibilities). The scale consists of 17 items in each part (34 items in the total), ranging from 1 (Never) to 5 (Always), distributed by four dimensions of family communication, namely: (1) confidence/ communication sharing from parents to children (5 items); (2) confidence/communication sharing from children to parents (5 items); (3) expression of affection and emotional support (4 items) and (4) negative communication pattern ( 3 items). In the interpretation of the results, higher scores reveal a better perception of parent-child communication, with the exception of the Negative Communication Pattern dimension, in which scoring higher values demonstrates a negative perception of communication (Portugal et al., 2019). In the original study of the COMPA-EA the scale globally revealed good levels of internal consistency (fathers' version $\alpha=.93$; mothers' version $\alpha=.92$ ), except for the dimension negative communication pattern (fathers' version $\alpha=.44$; mother's version $\alpha=.55$ ). In this study, the results also showed good internal consistency for the total scale $(\alpha=.90$ both for mother's and fathers' versions) and subscales (range from .93 to .83), except for the dimension negative communication pattern (fathers' version $\alpha=.61$; mother's version $\alpha=.57$ ).

\section{Differentiation of Self Inventory - Revised (DSI-R-20)}

A brief version of the Differentiation of Self Inventory - Revised (DSI-R; Sloan \& Dierendonck, 2016) it was used to evaluates the differenciation of self, i.e., the degree to which an individual can balance emotional with intellectual functioning and closeness with independence in relationships with others (Bowen, 1978). The 20 items are distributed by four factors: (1) emotional reactivity (ER), (2) ability to speak from the I-position (IP), (3) emotional cut-off (EC), and (4) fusion with others (FO). Bowen (1978) mentions that individuals with a high level of differentiation are not affected by emotional reactivity and group pressure, having more satisfactory relationships without fear of fusion (Relvas \& Major, 2014). Answers to the items are given on a Likert scale ranging from 1 (Nothing true for me) to 6 (Very true for $m e$ ). In the interpretation of the results, the higher the results obtained on the full scale and the subscales, the greater the differentiation of the self, meaning that the greater the ability to assume the position of the "I" in relationships and the lower the emotional reactivity, emotional cut-off and fusion with others With regard to psychometric characteristics, the reduced version revealed an acceptable internal consistency, both for the full scale $(\alpha=.90)$ and for the four subscales (ER $\alpha=.85$; IP $\alpha=.70$; EC $\alpha=.76$; FO $\alpha=.76$ ) (Sloan \& Dierendonck, 2016). In this study the full scale revealed a value of $\alpha=.71$ and the subscales values ranging from .78 and .58 . 
Brief Symptom Inventory (BSI)

Developed by L. Derogatis (1993), this inventory evaluates the presence of psychopathological symptoms and psychological distress. The Portuguese version used in this study was validated by Canavarro in 1999 and updated in 2007 (Canavarro, 2007). It is a self-report instrument, in a five-point Likert response format, ranging from 0 (Never) to 4 (Very often) and focuses on how the symptoms affected the individual in the past seven days. The presence of psychological symptoms is translated into higher score values. It has good psychometric proprieties and can be administered either to clinical or general populations (Canavarro, 2007). Although the inventory assesses nine dimensions, the present investigation only evaluated the following: Interpersonal Sensitivity, Depression, and Anxiety. These dimensions were chosen based on the current literature, that has connected feelings of inadequacy, anxiety and depression symptoms with addiction (Andreassen et al., 2016; Holmgren \& Coyne, 2017; Ryan et al., 2014), and diminished interpersonal capabilities with a preference for online communication (Caplan, 2010). Cronbach's alpha for the dimensions in the present study was: Depression subscale $\alpha$ $=.75$; Anxiety subscale $\alpha=.77$; Interpersonal Sensitivity $\alpha=.80$.

\section{Data analyses}

Statistical Package for the Social Sciences (SPSS), version 23, was used to record, process and analyze the collected data. Firstly, in order to understand the sample data, descriptive analyses were performed and then, internal consistency analyses were performed in order to identify the reliability of the instruments used, as determined by Cronbach's alpha.

In order to meet the objectives established for this study, namely the influence of sociodemographic, individual and family variables on Facebook addition, multiple hierarchical linear regression analyses were performed. In order to verify compliance with the assumptions of this type of analysis, it was necessary to group some variables, transforming them into dichotomous variables. With regard to Area of Residence, it was recoded only in "Rural" and "Urban", the latter grouping the "Semi-urban" option. Regarding the relationship status, it was transformed into two groups: individuals with a partner (including In a relationship, Living Together, Married, Remarried) and individuals without a partner (i.e. Single, Divorced or Widowed). Regarding the level of education, we decided to recode at two levels: (1) No academic degree, and (2) with an academic degree (grouping the subjects who have a bachelor's, master's or doctoral degree). Finally, the labour situation variable was also recoded, creating a group ("Employees") where part-time and full-time workers were included and another group that includes students and unemployed ("Not employed"). Then, for the construction of the model through the regression analysis, three blocks were constituted. The first block, which corresponds to the socio-demographic variables, concerns the gender, age, place and area of residence, whether or not the person has children, the relationship status, the level of education, the work situation and whether he/she plays any sport or hobby. The second block included the subscales on family communication (COMPA) and, finally, the third block included the individual dimensions related to the differentiation of the self (DSI-R). In order to fulfil the assumptions required in this analysis, we verified the collinearity, in which the tolerance values should move away from zero and those of FVCs below five (Pallant, 2011).

Finally, the correlation between the dimensions of BSI Anxiety, Depression and Interpersonal Sensitivity and BFAS, determined by Pearson's r-value, was also performed.

\section{Results}

Facebook Addiction: influence of sociodemographic variables, family communication and differentiation of self

Regarding the instrument evaluating Facebook Addition, the results showed the suitability of the regression model, $Z(22,353)=2.60, p<.001$. As shown in Table 3, Sex, Age, and Negative Comunicational Pattern regarding both parents and the fators Ability to speak from the I-position, and Emocional cut-off, explain $13.9 \%$ of the total variance. 
Table 3

Summary of Hierarchical Regression Analysis for Variables predicting Facebook Addiction.

\begin{tabular}{|c|c|c|c|c|c|c|c|c|c|}
\hline \multirow{2}{*}{ Variable } & \multicolumn{3}{|c|}{ Model 1} & \multicolumn{3}{|c|}{ Model 2} & \multicolumn{3}{|c|}{ Model 3} \\
\hline & $\beta$ & $\mathrm{t}$ & $p$ & $\beta$ & $\mathbf{t}$ & $p$ & $\beta$ & $\mathrm{t}$ & p \\
\hline Gender & -.109 & -2.038 & $.042^{*+}$ & -.070 & -1.223 & .222 & -.031 & -.555 & .579 \\
\hline Age & .067 & 1.057 & .291 & .070 & 1.096 & .274 & .132 & 2.100 & $.036^{*+}$ \\
\hline Residence Area & .002 & .031 & .976 & -.003 & -.052 & .959 & -.030 & -.599 & .549 \\
\hline Relationship Status & .028 & .539 & .590 & .011 & .206 & .837 & -.004 & -.078 & .938 \\
\hline Education & .041 & .665 & .507 & .034 & .552 & .581 & .051 & .852 & .395 \\
\hline Occupational Status & -.079 & -1.504 & .133 & -.077 & -1.454 & .147 & -.083 & -1.612 & .108 \\
\hline Sports practice & -.057 & -1.037 & .301 & -.053 & -.975 & .330 & -.081 & -1.530 & .127 \\
\hline Hobbies & -.054 & -.991 & .322 & -.046 & -.836 & .403 & -.033 & -.631 & .528 \\
\hline $\begin{array}{l}\text { Parental confidence/ } \\
\text { sharing [Father] }\end{array}$ & & & & -.115 & -1.056 & .292 & -.128 & -1.208 & .228 \\
\hline $\begin{array}{l}\text { Children confidence/ } \\
\text { sharing [Father] }\end{array}$ & & & & .096 & .961 & .337 & .087 & .900 & .369 \\
\hline $\begin{array}{c}\text { Emotional support/ } \\
\text { affective expression } \\
\text { [Father] }\end{array}$ & & & & .113 & 1.009 & .314 & .133 & 1.226 & .221 \\
\hline $\begin{array}{c}\text { Negative } \\
\text { Communication } \\
\text { patterns [Father] }\end{array}$ & & & & -.133 & -2.121 & $.035^{*}$ & -.100 & -1.639 & .102 \\
\hline $\begin{array}{l}\text { Parental confidence/ } \\
\text { sharing [Mother] }\end{array}$ & & & & -.045 & -.403 & .687 & -.053 & -.489 & .625 \\
\hline $\begin{array}{l}\text { Children confidence/ } \\
\text { sharing [Mother] }\end{array}$ & & & & -.050 & 1.352 & .177 & .099 & .996 & .320 \\
\hline $\begin{array}{c}\text { Emotional support/ } \\
\text { affective expression } \\
\text { [Mother] }\end{array}$ & & & & -.050 & -.485 & .628 & -.039 & -.392 & .696 \\
\hline $\begin{array}{c}\text { Negative } \\
\text { Communication } \\
\text { patterns [Mother] }\end{array}$ & & & & -.124 & -2.106 & $.036^{*}$ & -.054 & -.905 & .366 \\
\hline Emotional Reactivity & & & & & & & .134 & 1.893 & .059 \\
\hline $\begin{array}{l}\text { Ability to speak from } \\
\text { the I-position }\end{array}$ & & & & & & & -.109 & -2.042 & $.042^{*+}$ \\
\hline Emotional Cut-off & & & & & & & .134 & 2.264 & $.024^{*+}$ \\
\hline Fusion with others & & & & & & & .034 & .489 & .625 \\
\hline
\end{tabular}

Facebook Addiction: influence of sociodemographic variables, family communication and differentiation of self

Regarding the instrument evaluating Facebook Addition, the results showed the suitability of the regression model, $Z(22,353)=2.60, p<.001$. As shown in Table 3, Sex, Age, and Negative Comunicational Pattern regarding both parents and the fators Ability to speak from the I-position, and Emocional cut-off, explain $13.9 \%$ of the total variance.

Specifically, gender presents a negative association with the dependent variable in the first model, which means that females present higher levels of Facebook addition. Regarding family variables, the Negative Communicational Pattern dimension presents, in the second model, a negative association with the variable, showing that certain communicational behaviors that promote uneven relationship styles between children and both parents are associated with the Facebook addition (see Table 3).

Regarding the third model, the age variable shows a positive association with Facebook addition, which indicates that older age, namely between 24 and 30 years, are is associated with a higher addition. Regarding the Differentiation of Self, there is a positive association with the Emotional Cutoff, which indicates that individuals who are emotionally and physically distanced from their families or others are associated may present higher Facebook addiction. The "l" position dimension shows that a low differentiation of the self (individuals who have more difficulty in assuming their ideas and opinions) is associated with higher scores for Facebook Addiction (see Table 3).

Correlations between BFAS scores and BSI

Finally, a correlation analysis was performed (Pearson's $r$ ) between the Interpersonal Sensitivity, Depression and Anxiety dimensions of the BSI inventory and BFAS scores, with a significant correlation being found between all psychopathological indicators evaluated and Facebook Addiction (see Table 4). 
Table 4

Correlations between Facebook Addiction and subscales.

\begin{tabular}{lc}
\hline Subscales & Facebook Addiction \\
\hline Interpersonal Sensitivity & $.17^{\star *}$ \\
Depression & $.15^{* \star}$ \\
Anxiety & $.18^{* \star}$ \\
\hline Note. ${ }^{* *} p<.001$ &
\end{tabular}

\section{Discussion}

This study sought to identify the sociodemographic, individual and family variables that may promote Facebook Addition in emerging adults. The results obtained allow us to conclude: (1) gender and age emerge as sociodemographic variables determining the Facebook Addiction in emerging adults, with women aged between 24 and 30 being the group most likely to develop this addition; (2) negative communication patterns with father and mother figures are influential family variables in Facebook Addiction and, finally (3) the position of the I and the Emotional Cut-off are individual variables related to the Differentiation of Self that influence Facebook Addiction in emerging adults.

With regard to gender influence, the study corroborates the conclusions of previous studies, in which there was a predominance of females among Facebook users (Przepiorka \& Blachnio, 2016). This result may probably be associated with the fact that SNSs are more attractive applications for women (Przepiorka \& Blachnio, 2016). According to some authors (Andreassen \& Pallensen, 2014), female influence in some studies may however derive from sample characteristics, given the higher number of female subjects in the studied samples.

Regarding age, we found in this study that individuals aged between 24 and 30 years reveal higher scores in BFAS, thus revealing age as a determining factor in Facebook Addiction. Contrary to the trend observed in this study, in which older individuals appear associated with a higher score on the Facebook addiction scale (BFAS), other studies have indicated that an average age of 21.41 years is related to higher levels of addition to Facebook (da Veiga et al., 2019). For this reason, it is important in future continue to study the influence of age on Facebook addiction, seeking to clarify what its role is in determining this behavior.

Concerning family communication, it was found that the negative communication pattern between children and parents is associated with higher Facebook Addiction (i.e., higher scores in BFAS). There are also studies that show that Facebook Addiction has an impact on the relationship between children and parents, demonstrating that individuals with an anxiogenic relationship with their parents spend more time on Facebook (Moreau et al., 2015) and that the different technologies may have a negative influence on family communication and impact the quality of relationships (Carvalho et al., 2017). Thus, the family context seems to have great importance with regard to the analysis of technological additions, since the introduction of ICTs within the family has brought about several changes in family life, particularly regarding communication (Carvalho, Francisco \& Relvas, 2015). As mentioned in a study on Internet addiction (Pontes et al., 2016), this is not only an individual's problem but also that of the family, i.e., the system in which the individual is inserted. Thus, this study shows that a negative communicational style with parents may lead to higher levels of Facebook Addiction.

Regarding individual characteristics, we analyzed the differentiation of self in its intrapersonal component, through the dimension "I Position", demonstrating that a low self differentiation can determine greater Facebook Addiction. There are few studies that focusing on this relationship; however, there are some results in the literature that assess this dimension in relation to pathological gambling (Cunha, Sotero, \& Relvas, 2018). It was found that difficulties in Differentiation of Self are associated with higher levels of severity of pathological gambling, showing that they have greater difficulty in establishing their beliefs, depending on others to reaffirm and approve them and also a greater tendency to react to environmental stimuli based on automatic responses (Cunha et al., 2018). These data can be seen as going against those verified in this research, in which a low Differentiation of Self associated with higher levels of Facebook addiction, also considering this addition also as a pathological behavior (Griffiths, 2005).

According to Bowen (1978), this intrapersonal component of self-differentiation ("l" position) is related to the ability to maintain a balance between cognitive and emotional aspects that may deteriorate into disharmony when there is a low differentiation of the self. Thus, individuals with low differentiation demonstrate permissiveness or inflexibility at their limits, are less adaptive, tend to adopt the convictions, beliefs and positions of others such as themselves (Sloan \& Dierendonck, 2016) and, consequently, are more vulnerable to stress, which may lead them to give in to group and external pressure (Bowen, 1978). In fact, in a SNS such as Facebook, there is the expression of different opinions, beliefs, and 
attitudes of different users, which may condition or influence other users of the network to take the same positions, especially if there is a low differentiation of the self as a weakness.

Another aspect related to the differentiation of self, integrated in the interpersonal component, highlighted in this study is the Emotional Cut-off. This dimension seems to somehow determine Facebook Addiction, noting that a higher score in the Emotional Cut-off determines a higher score in Facebook Addiction. There are some references in the literature that indicate that a greater investment in online relationships may lead to a social estrangement (Pontes et al., 2014). This dimension is also indicated in the literature as a behavioral mechanism for managing emotions, and individuals in response to situations of anxiety or stress tend to merge or break down emotionally in significant relationships (Bowen, 1978). Given the results of this study, a physical and emotional distance in the relationship with significant others seems to contribute to a greater Facebook Addiciton, with possible relevance to the relationships established online, neglecting the individual's activities and people from his offline life.

Self differentiation and emerging adulthood are variables that somehow interconnect and there seem to be some points that intersect in these two aspects. According to Bowen (1978), the level of differentiation tends to be established at this stage of development, namely when young adults separate from their family of origin. This seems to be a more delayed process today, since data indicate that young Portuguese adults stabilise their lives, both personally (e.g., birth of the first child after the age of 30) and professionally (e.g., duration of higher education; prolonged job instability) later on (Carvalho et al., 2015). In addition, emerging adulthood can be seen as a phase of discovery, change, exploitation (Arnett, 2000) and even of some fragility, for all the characteristics involved and for a look at the future seen as a great responsibility and, sometimes, "frightening" for the responsibility it entails.

Finally, in reporting to the analysis of psychopathological symptoms there was a significant correlation between the dimensions interpersonal sensitivity, depression and anxiety and Facebook Addiction. Analyzing the literature, some studies seem to corroborate the results obtained, also demonstrating high scores in the three dimensions mentioned regarding Facebook addiction (da Veiga et al., 2019) and a positive association between mental health problems and a problematic use of Facebook (Moreau et al., 2015). Some authors clarify this relationship by stating that users with depressive symptoms tend to overuse Facebook to self-regulate their mood (Hong et al., 2014), and higher levels of depression correlate with a higher addition, as found in this study. With regard to anxiety, there are also studies that report that individuals with anxiety symptoms tend to spend more time on Facebook, as a way to compensate for their low self-esteem and their poor ability to communicate face to face.

In conclusion, this study allows us to conclude that sociodemographic variables (gender and age), family variables (communication pattern with both parents) and individual variables (Position of the "I" and Emotional Cut-off) influence Facebook addicton. Therefore, in clinical and preventive implications, where it is essential to intervene in terms of online addictive behaviours, and there are some studies, albeit scarce, that identify as necessary and effective interventions at an individual (e.g., Cognitive Behavioural Therapy), family and group level, as well as the use of psychoactive drugs in combination with these forms of psychotherapy. The results of this study highlight the need and importance of acting in the family context, since this issue is related to individual aspects (gender, age, differentiation of the self) as well as family aspects (parent-child communication), affecting not only the individual but also those around him (Patrão et al., 2016). Regarding the prevention of these behaviours, the Facebook addiction scale (BFAS) is highlighted as an important instrument to identify risk signals in its users and thus prevent the consequent addiction.

\section{Limitations and Future Studies}

In this research, some limitations were identified. Regarding characteristics of the sample, which was collected through convenience sampling, there was a disproportion regarding the number of female and male participants, with a higher prevalence of the former. Also with regard to the employment situation, there was a higher number of students compared to other groups, which reflected the period of development studied.

Although this research has presented some relevant considerations, it would be useful to replicate this study through a longitudinal analysis, which may reveal clearer and more concise conclusions. As a suggestion, it might also be relevant to conduct future studies in relation to other social networks that have recently gained prominence and popularity (e.g., Instagram). 


\section{References}

5. Andreassen, C. S., Torsheim, T., Brunborg, G. S., \& Pallesen, S. (2012). Development of a Facebook addiction scale. Psychological Reports, 110, 501-517. https://doi.org/10.2466/02.09.18. PR0.110.2.501-517

6. Andreassen, C. S., \& Pallensen, S. (2014). Social network site addiction-an overview. Curr. Pharm. Des., 20, 4053-4061.https://doi.org/10.2174/13816128113199990616

7. Andreassen, C. (2015). Online Social Network Site Addiction: A Comprehensive Review. Technology and Addiction, 2, 175-184. https://doi.org/10.1007/s40429-015-0056-9

8. Arnett, J. J. (2000). Emerging adulthood: A theory of development from the late teens through the twenties. American Psychologist, 55, 469-480. https://doi.org/10.1037//0003-066X.55.5.469

9. Bowen, M. (1978). Family therapy in clinical practice. Northvale, NJ: Jason Aronson, Inc.

10. Boyd, D. M., \& Ellison, N. B. (2008). Social network sites: Definition, history, and scholarship. Journal of Computer-Mediated Communication, 13, 210-230. https://doi.org/10.1111/j.10836101.2007.00393.x

11. Çam, E., \& Ístambul, O. (2012). A new addiction for teacher candidates: Social networks. The Turkish Online Journal of Education Technology, 11, 14-19.

12. Caplan, S. E. (2010). Theory and measurement of generalized problematic internet use: a two-step approach. Computers in Human Behavior, 26, 1089-1097. https://doi.org/10.1016/j. chb.2010.03.012

13. Carvalho, J., Francisco, R., \& Relvas, A. (2015). Family functioning and information and communication technologies: How they relate? A literature review. Computers in Human Behavior, 45, 99-108. https://doi.org/10.1016/j.chb.2014.11.037

14. Carvalho, J., Francisco, R., \& Relvas, A. P. (2017). ICTs and family functioning: a study on Portuguese families with adolescents and emerging adults. Contemporary Family Therapy, 39, 281 288. https://doi.org/10.1007/s10591-017-9436-8

15. Chabrol, H., Laconi, S., Delfour, M., Moreau, A. (2017). Contributions of psychopathological and interpersonal variables to problematic facebook use in adolescents and young adults. Int. J. High. Risk Behav. Addict, 6. https://doi.org/10.5812/ijhrba.32773

16. Coyne, S. M., Padilla-Walker, L. M., \& Howard, E. (2013). Emerging in a digital world: A decade review of media use, effects, and gratifications in emerging adulthood. Emerging Adulthood, 1, 125-137. https://doi.org/10.1177/2167696813479782

17. Cunha, D., Sotero, L., \& Relvas, A. P. (2018). Diferrentiation of self and gambling behavior severity: a comparative analysis. Comunicação oral. Estudo não publicado.

18. Griffiths, M. (2005). A 'components' model of addiction within a biopsychosocial framework. Journal of Substance Use, 10, 191197. https://doi.org/10.1080/14659890500114359

19. Griffiths, M. (2013). Social networking addiction: Emerging themes and issues. Journal of Addiction Research and Therapy, 4, 1-2. https://doi.org/10.4172/2155-6105.1000e118

20. Hargittai, E. (2007). Whose space? Differences among users and non-users of social network sites. Journal of Computer-Mediated Communication, 13, 276297. https://doi.org/10.1111/j.10836101.2007.00396.x

21. Holmgren, H. G., \& Coyne, S. M. (2017). Can't Stop scrolling!: pathological use of social networking sites in emerging adulthood. Addiction Research \& Theory, 25, 375-382. https://doi.org/10.10 80/16066359.2017.1294164

22. Instituto Nacional de Estatística. (2015). Inquérito à Utilização de Tecnologias da Informação e da Comunicação pelas Famílias. Retirado de: https://www.ine.pt/ngt_server/attachfileu.jsp?look_parentBoui=24584 4025\&att_display=n\&att_download=y:

23. Kuss, D., \& Griffiths, M. D. (2011). Online Social Networking and Addiction - A Review of the Psychological Literature. International Journal Of Environmental Research and Public Health, 8 , 3528-3552. https://doi.org/10.3390/ijerph8093528

24. Kuss, D., \& Griffiths, M. D. (2017). Social Networking Sites and Addiction: Ten Lessons Learner. International Journal of Environmental Research and Public Health, 14, 311. https://doi. org/10.3390/ijerph14030311

25. Kuss, D. J., \& Billieux, J. (2016). Technological addictions: Conceptualisation, measurement, etiology and treatment. Addictive Behaviors, 64, 231-233. https://doi.org/10.1016/j. addbeh.2016.04.005

26. MCAndrew, F. T., \& Jeong, H. S. (2012). Who does what on facebook? Age, sex, and relationship status as predictors of facebook use. Computers in Human Behavior, 28, 2359-2365. https://doi. org/10.1016/j.chb.2012.07.007 
27. Moreau, A., Laconi, S., Delfour, M., \& Chabrol, H. (2015). Psychopathological profiles of adolescent and young adult problematic Facebook users. Computers in Human Behavior, 44, 64-69.

28. Pallant, J. (2011). SPSS Survival Manual. A step by step guide to data analysis using SPSS $\left(4^{\text {th }}\right.$ ed. $)$. Australia: Allen \& Unwin.

29. Perrin, A. (2015). Social media usage: 2005-2015. Pew Internet \& American Life Project. Retrieved from: http://www.pewinternet.org/2015/10/08/socialnetworking-usage-2005-2015/

30. Portugal, A. P., Beja, M. J., Cunha, D., Camacho, F., Spínola, J., \& Santos, A. (2019). Emerging adulthood and parent-child communication: A validation study with Perception Scale of Parenting Communication. International Journal of Psychology \& Psychological Therapy, 19, 203-215. The original publication is available at https://www.ijpsy.com/volumen19/num2/517.html

31. Przepiorka, A., \& Blachnio, A. (2016). Time perspective in Internet and Facebook addiction. Computers in Human Behaviour, 60,13-18. https://doi.org/10.1016/j.chb.2016.02.045

32. Relvas, A. P., Fonseca, G., Baião-Traguedo, T., Major, S., \& RodriguezGonzález, M. (2017). Inventário da Diferenciação do Self - Revisto. Manuscrito submetido para publicação.

33. Ryan, T., Chester, A., Reece, J., \& Xenos, S. (2014). The uses and abuses of Facebook: A review of Facebook addiction. Journal of Behavioral Addictions, 3, 113-148. https://doi.org/10.1556/ JBA.3.2014.016

34. Sloan, D., \& van Dierendonck, D. (2016). Item selection and validation of a brief, 20-item version of the Differentiation of Self Inventor - Revised. Personality and Individual Differences, 97, 146150. https://doi.org/10.1016/j.paid.2016.03.037

35. Song, I., Larose, R., Eastin, M. S., \& Lin, C. A. (2004). Internet gratifications and internet addiction: On the uses and abuses of new media. CyberPsychology \& Behavior, 7, 384-394. https:// doi.org/10.1089/cpb.2004.7.384

36. Soron, T. R., \& Tarafder M. A. (2015). The relation between facebook use pattern and Demographic factors. J Psychiatry 18, 326. https://doi.org/10.4172/2378-5756.1000326

37. Statista (2019). Portugal: monthly number of Facebook users 2018-2019. Retrieved from https:// www.statista.com/statistics/1017409/facebook-users-portugal/.

38. da Veiga, G., Sotero, L., Pontes, H. Cunha, D., Portugal, A., \& Relvas, A. P. (2019). Emerging Adults and Facebook: Bergen Facebook Addiction Scale (BFAS) Portuguese Validation Studies. International Journal of Mental Health and Addiction, 17, 279-294. https://doi.org/10.1007/ s11469-018-0018-2

RECIBIDO: 15 de octubre de 2019

MODIFICADO: 21 de junio de 2020

ACEPTADO: 22 de 26 de 2020 